\title{
Study on Campus Security Legislation
}

\author{
Mei Liu \\ Kunming University \\ Kunming, China
}

\begin{abstract}
At present, there is no single law in China that specifically regulates campus security issues. Only some relevant basic laws have provisions on campus security issues or have principled provisions. The legislation of the Campus Security Law should be initiated as soon as possible. Through the campus security legislation, we establish a set of laws and regulations and institutional measures to regulate campus security management, and integrate campus security work into the track of legal management.
\end{abstract}

Keywords-campus security; legislation; campus security law

\section{INTRODUCTION}

At present, public security issues in schools cannot be ignored. Typical explosions in Tsinghua University and Peking University, SARS transmission of Northern Jiaotong University, fire case in Xundian of Yunnan province, poisoning case of Jiangsu primary and secondary schools, and stamping of Kunming primary school in Yunnan province have bad impact on the schools and the society. Relevant legal relationships and disputes cannot be avoided, and the campus security situation is urgent. This shows that there are quite serious problems in the public security environment of our schools. Campus security requires corresponding legal environment. The campus security legislation has high voice, which has also attracted the attention of the legal profession, the education sector and the community. This article talks about a few rough views.

\section{OVERVIEW OF INTERNATIONAL CAMPUS SECURITY LEGISLATION}

There are many foreign experiences that can be learned from effectively protecting the safety of students in school and dealing with campus injuries through the legal system. As early as the last century, developed countries such as the United States and Japan have taken the establishment of a safe school as one of the national educational goals. Based on the Campus Security Law, a comprehensive set of campus security laws and regulations have been gradually established. The system has established a safe working system including campus police and specialized agencies.

In 1994, the US Congress passed the Goals 2000: Educated America Act, which increased the national education target to eight, with the seventh goal of "safe schools". In order to achieve this goal, the US Congress passed the Safe Schools Act of 1994 in the same year to help local school districts achieve safer federal programs, encouraging them to eliminate crime, violence, drug use, and bad discipline. They compete to get federal funding. In addition, the US legislation on campus security includes the GFSA, the IASA, the Campus, SDFSCA, etc. The states have their own legislation. Looking at the laws and regulations on US campus security, it is all-encompassing and covers almost every aspect.

Japan has always been one of the safest countries in the world with good social security and low criminal rates. However, its campus security is also a problem that many educators and management are deeply disturbed and trying to solve through legislation. The Japanese Parliament reviewed and passed the School Safety Association Act in December 1959, which divided school safety into two major parts: security education and security management. All schools must establish security management regulations to explain security knowledge and skills to students. It will prevent problems before they happen. Subsequently, the "Sports Promotion Law", the "School Health Care Law" and the "School Food Supply Law" were successively promulgated or revised. On this basis, the campus security system with sports, health care and food supply as the main content was initially established.

The UK is one of the countries focusing on campus security issues. There are many successful experiences in maintaining campus security that are worth learning. As a typical representative country with the common law system, the United Kingdom is deeply influenced by the tradition of jurisprudence. Therefore, the statute law in campus security management is not as developed as the United States. It has increased legislative strength in campus security in response to the increasingly severe campus security in recent years. For example, in order to eliminate school violence, the British Parliament enacted the Education and Inspection Act in 2007, which expanded the school's jurisdiction over noncompliant students.

In addition, countries such as Australia and Sweden have also developed the Campus Safety Law that suits their national conditions. The laws are powerful weapons for these countries to safeguard school safety, effectively prevent and combat all kinds of illegal criminal activities that endanger the safety of teachers and students. The legislative experience of these countries can be used as an important reference for the formulation of the Campus Safety Law and supporting legal norms in China. 


\section{THE NECESSITY OF CAMPUS SECURITY LEGISLATION}

\section{A. It Is the Objective Need to Effectively Protect the Legitimate Rights and Interests of Students}

The frequent occurrence of school safety accidents has sounded the alarm to the whole society and has aroused great concern from the whole society. Therefore, it is an urgent task to protect the life and safety of students in school. Most of the students in primary and secondary schools are those without civil capacity and those with limited capacity for civil conduct. We should have clear legal protection for their health and safety of life. The majority of students in higher education institutions (including private colleges and universities) have civil capacity. However, they are still among the special groups of students, and the security issues cannot be ignored. Therefore, the safety of college students is also in urgent need of legal protection. This requires the establishment of clear legal norms and specific safeguards to protect the health, safety and legal rights of students.

\section{B. It Is the Practical Need to Ensure the Normal Teaching Order of the School}

According to China's "General Principles of Civil Law", "Education Law", "Teacher Law", "Law on the Protection of Minors" and other laws, the school is the educator, administrator and protector of the students, and has the responsibilities of education, management and protection for the students during the school. Therefore, schools should take safety measures, pay attention to safety precautions, protect the legitimate rights and interests of students, and ensure the smooth progress of the entire education and teaching activities. The current laws such as the "General Principles of the Civil Law", the "Education Law", and the "Law on the Protection of Minors" does not clearly define the school safety issues. There are great differences in judicial practice. Similar injury incidents occur in different regions and are concluded by different courts, and the results may be biased. Therefore, the formulation of the "School Security Law" and the clarification of the legal relationship between the school and the students can fill the legal gap in this area. The handling of school safety accidents will have the law to follow. The manager of the school will follow the law.

\section{THE FEASIBILITY OF CAMPUS SECURITY LEGISLATION}

\section{A. Theoretical Research on Campus Security Legislation Has Laid a Theoretical Foundation for the Formulation of the Campus Security Law}

In recent years, people in the education and legal circles in China have published a large number of articles, and have conducted in-depth discussions on theoretical issues related to campus security legislation. Various proposals put forward by these theoretical studies on the campus security law can provide an important reference for the formulation of the campus security law in China.

\section{B. China's Past Campus Security Legislation Has Accumulated Legislative Experience for the Formulation of the Campus Security Law}

For some complicated central legislative projects, the safer way to make the promotion is to "make the pilot project in the local areas, and then in the central". In this way, local legislation will accumulate rich experience for central legislation and facilitate the scientific nature of central legislation. In view of the complexity of school safety issues, this should also be used in school safety legislation in China. To our pleasure, some local standing committees of people's congress have made useful explorations on school safety legislation. The Regulations on the Handling of Student Injury Accidents in Shanghai primary and secondary schools came into effect on September 1, 2001. Since then, the "Regulations on the Prevention and Treatment of Personal Injury Accidents of Primary and Secondary School Students in Beijing", "School Safety Regulations of Ningbo City", "Campus Security Regulations of Shenzhen city", "School Safety Regulations of Liaoning Province", "School Safety Regulations of Heilongjiang Province" and other local regulations have been introduced. Compared with the "Measures for Handling Student Injury Accidents" formulated by the ministry of education, these local regulations pay more attention to the safety management of schools and regard the prevention of safety incidents as the focus of school safety work. The local school safety legislation in China has accumulated certain legislative experience for the formulation of the campus security law.

\section{THE PRINCIPLES OF CAMPUS SECURITY LEGISLATION}

\section{A. Security First}

Ensuring the safety of students is a prerequisite for normal education and teaching. Therefore, security first must become the first principle of campus security legislation. The "security" here mainly refers to the personal safety of students. Since the personal safety of students is the most common cause of campus security accidents, it is necessary to implement the concept of "security first" when formulating campus security regulations. It should be student-oriented.

\section{B. Prevention First}

The fundamental purpose of campus security legislation is to prevent and reduce the occurrence of campus security accidents, not just to deal with and to compensate after the accident. Therefore, the legislation should pay attention to the formulation and implementation of the school safety precaution management system. It clearly stipulates that the school and all relevant parties should find out the links, locations and time periods of the prone accidents through the investigation. We must actively and scientifically make the prevention. At the same time, we will improve the safety system, eliminate potential safety hazards, and ensure the safety of students. 


\section{Comprehensive Governance}

The activities of the school are not single, and they are integrated organism that is associated with all aspects of society For example, there is the affiliation relationship between the school and the competent education department. There is education and management relationship between the school and the students. There is equal civil subject relationship among the school, parents and society. Due to the special nature of the school, campus security is naturally not just a problem of the school. Therefore, campus security legislation can not only be centered on the campus. We should implement the principle of comprehensive governance, and consider the possible effects of formulating laws and regulations from all aspects. The society, schools and families form a unified body, creating a good education and teaching surroundings for the schools.

\section{CONSTRUCTION OF THE CONTENT SYSTEM OF CAMPUS SECURITY LEGISLATION}

\section{A. To Determine the Connotation and Scope of Campus Security}

For the connotation and scope of school safety, there are greater differences: to determine the scope of the school; How should the connotation of safety be defined? Is it limited to the personal safety of students, or the personal and property safety of teachers, staff and students?

\section{B. To Clarify the Source of Campus Security Funding}

The funding problem is the key to solve the current school safety work. In recent years, all localities have paid great attention to the investment in school teaching facilities. However, they often neglect the investment in school safety facilities. Therefore, it is recommended to set up special funds to be written into the law for the repair and renovation of school buildings and fire-fighting facilities to ensure the source of school safety work.

\section{To Clarify Campus Security Responsibilities}

School safety work is the common responsibility of the government and its relevant competent departments and the whole society. The government has the responsibility of leadership, coordination, supervision and inspection. The education authorities have major management responsibilities, and other competent departments have their own responsibilities for good school safety work. In order to enhance the safety awareness of the government and its relevant authorities and clarify their responsibilities, it is necessary to decompose and refine the responsibilities of the people's governments at or above the county level and the education, public security, construction, and health authorities in the legislative process, and stipulate corresponding legal liability.

\section{To Standardize Campus Security Management}

Most school safety incidents occur when you are on campus or when you organize off-campus activities. The causes of school safety incidents are complex, involving many aspects. Therefore, it is necessary to put forward more detailed requirements for the safety management of oncampus and off-campus activities, and to clarify the school's safety management responsibilities. In legislation, schools should be required to establish security education, emergency reporting and response working system. The schools should make detailed stipulation in security management responsibilities in the implementation of safety measures, school safety, fire safety, safety of special facilities and equipment, school bus safety, and dangerous goods management, food and drug supplies safety, campus health and epidemic prevention, education and teaching activity safety, large-scale event safety, boarding student management, school leaving management, student health, special faculty management, and hidden danger reporting. At the same time, it should also clarify the legal responsibilities of the school for failing to perform its safety management duties.

\section{E. To Clarify the Accident Identification and Handling Procedures}

The identification and handling procedures of school safety accidents are issues of great concern to the education department, schools and parents, and are also difficult issues in legislation. In order to ensure fair and reasonable handling of school safety incidents, the author believes that in the development of the campus safety law, the responsibility of the education, management and protection of the government, its departments and the school should be clarified. At the same time, clear and specific provisions should be made for the investigation and handling procedures of accidents, the main body of accident investigations, and the handling of damages disputes. Specifically, it includes procedures such as notification, rescue, accident reporting, guidance and assistance, mediation and litigation.

\section{CONCLUSION}

In summary, the real obstacle to the delay in the implementation of the campus security law is that we still lack sufficient theoretical reserves for the formulation of such a law. Whether it is education or law, there is still no convincing judgment or choice about the objectives, functions, models and principles of school safety legislation. There is also a lack of clear structure for the system profile of this law. Campus security legislation must first determine the status of the campus security law in China's legal system. The adjustment targets and scope of the campus security law mainly refer to school definition, definition of campus security representatives, campus definition, and so on. In China's large and diverse schools at all levels, it is not a simple matter to succinctly define the scope of campus safety adjustments. In terms of the definition of schools and students with the closest safety and social concerns to the campus, the legal responsibilities of the schools and related legal responsibilities of the students at the higher, middle and primary levels are also involved. It also includes schools of different natures (such as schools, enterprises, social organizations, other social organizations, and various types of schools organized by citizens), the clarification of the 
administrative power of campus security, and also involve schools at all levels of schools, and the specific implementation of security administrative authority. The adjustment methods and law enforcement authority of "campus security law" involves civil law, administrative law, social law, and even penal law. The current status quo is often long-term management. In fact, it is difficult to implement long-term management. The reason for this situation is that the law enforcement subject of campus security is not clear; the second is that the law enforcement authority of the school as a campus administrator is not clear. First of all, it is necessary to clarify and strengthen the law enforcement subject of the campus security law. However, due to the particularity and diversity of the campus security law enforcement subject, it not only relates to the relationship between the legal person of the school and the law enforcement subject of the campus security law, but also involves the relationship between the adjustment structure of the security law and the social public safety system. In short, we need long-term and unremitting efforts of theoretical circles and practitioners to clarify these difficult problems before we can construct a clear, rigorous, standardized and practical "campus security law".

\section{REFERENCES}

[1] Qu Zhengwei. Some thoughts on formulating the "campus security law" [J]. Teaching and Management, 2001 (7).

[2] Fan Xufeng. The NPC deputies called for: Campus security legislation is imminent [N]. China Education News, 2004, 03, 15.

[3] Tang Jingli, Zhai Bo. Safeguarding campus security is an urgent task: more than 150 representatives call for the enactment of the campus security law as soon as possible [N ]. China Education News, 200103-08.

[4] Zhang Weiping, Weng Yingxiu. Research on the basic theoretical issues of the legislation of the campus security law [J]. Journal of Shenyang Normal University (Social Science Edition), 2004(4).

[5] Zheng Buying. Several issues on campus security legislation[J] . Journal of Wuhan University (Philosophy and Social Sciences), 2005(4). 